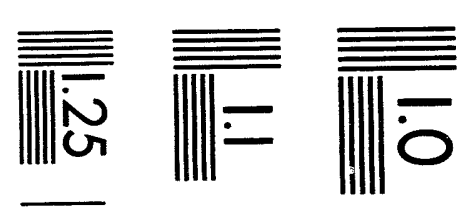

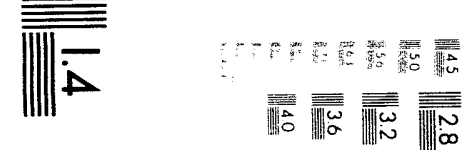

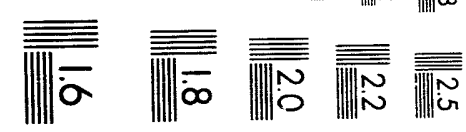



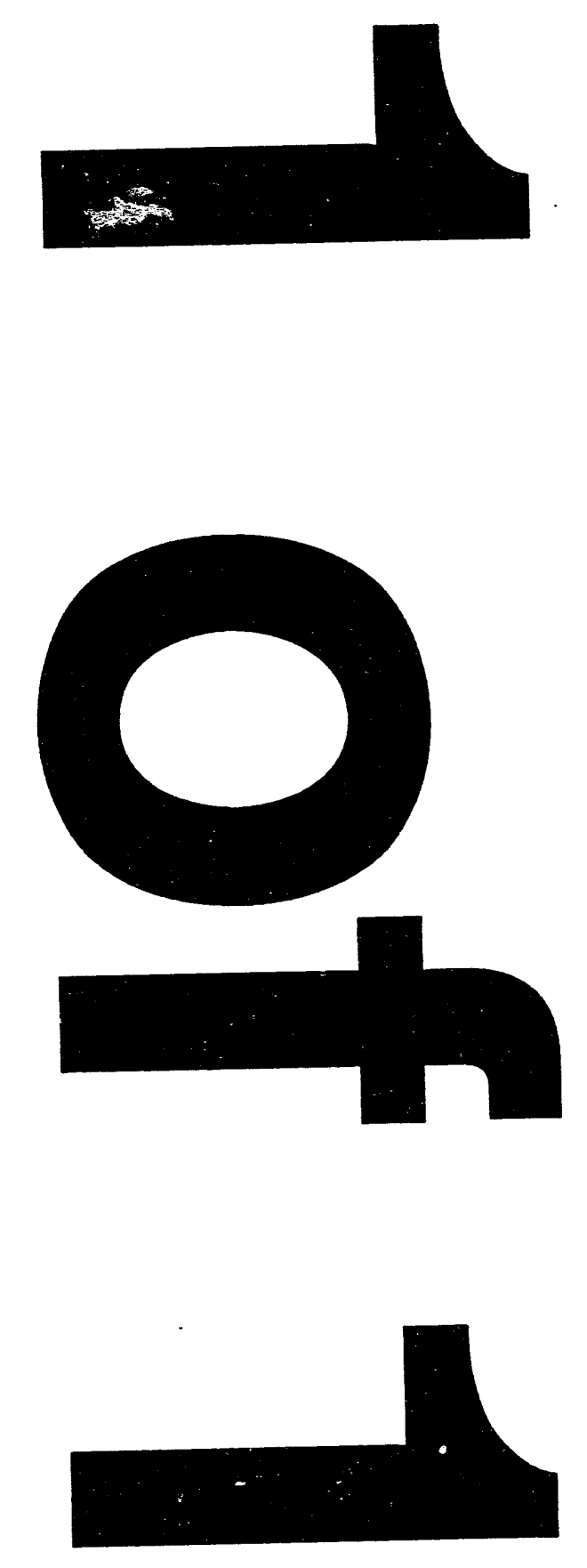


\title{
LATE WASH/NITRIC ACID FLOWSHEET HYDROGEN GENERATION BASES FOR SIMULATION OF A DEFLAGRATION/DETONATION IN THE DWPF CPC (U)
}

\author{
by \\ J. A. Ritter \\ Westinghouse Savannah River Company \\ Savannah River Site \\ Aiken, South Carolina 29808
}

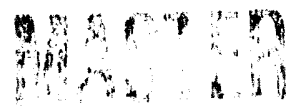

DOE Contract No. DE-AC09-89SR18035

This paper was prepared in connection with ivork done under the above contract number with the $U$. S.

Department of Energy. By acceptance of this paper, the publisher and/or recipient acknowledges the U. S. Government's right to retain a nonexclusive, royalty-free license in and to any copyright covering this paper, along with the right to reproduce and to authorize others to reproduce all or part of the copyrighted paper. 


\section{DISCLAIMER}

This report was prepared as an account of work sponsored by an agency of the United States Government. Neither the United States Government nor any agency thereof, nor any of their employees, makes any warranty, express or implied, or assumes any legal liability or responsibility for the accuracy, completeness, or usefulness of any information, apparatus, product, or process disclosed, or represents that its use would not infringe privately owned rights. Reference herein to any specific commercial product, process, or service by trade name, trademark, manufacturer, or otherwise does not necessarily constitute or imply its endorsement, recommendation, or favoring by the United States Government or any agency thereof. The views and opinions of authors expressed herein do not necessarily state or reflect those of the United States Government or any agency thereof.

This report has been reproduced directly from the best available copy.

Available to DOE and DOE contractors from the Office of Scientific and Technical Information, P. O. Box 62, Oak Ridge, TN 37831; prices available from (615) $576-8401$.

Available to the public from the National Technical Information Service, U. S. Department of Commerce, 5285 Port Royal Rd., Springfield, VA 22161 


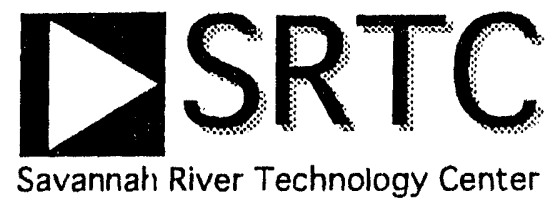

cc: R. A. Jacobs, 704-T

J. A. Zamecnik, 704-1T

N. D. Hutson, 704-1T

C. W. Hsu, 704-1T

J. T. Carter, 704-1T

L. F. Landon, 704-T

E. W. Holtzscheiter, 773-A

WSRC Records (4)

Retention: Permanent

Keywords: IDMS, Pilot-Scale

May 7, 1993

To: M. D. Boersma, 704-T

From: J. A. Ritter, 704-1T faunA.
LATE WASH/NITRIC ACID.FLOWSHEET HYDROGEN GENERATION BASES FOR
SIMULATION OF A DEFLAGRATION/DETONATION IN THE DWPF CPC (U)

SUMMARY

Hydrogen generation data obtained from IDMS runs PX4 and PX5 will be used to determine a bases for a deflagration/detonation simulation in the DWPF CPC. This simulation is necessary due to the new chemistry associated with the Late Wash/Nitric Acid flowsheet and process modifications associated with the presence of $\mathrm{H}_{2}$ in the offgas. The simulation will be performed by Professor Van Brunt from the University of South Carolina. The scenario which leads up to the deflagration/detonation simulation will be chosen such that the following conditions apply.

The SRAT is filled to its maximum operating level with 9,600 gal of sludge, which corresponds to the minimum vapor space above the sludge. The SRAT is at the boiling point, producing $\mathrm{H}_{2}$ at a very low rate (about $10 \%$ of the peak) and $15 \mathrm{scfm}$ of air inleakage is entering the SRAT. Then, the $\mathrm{H}_{2}$ generation rate will be allowed to increase exponentially (catalyst activation) until it reaches the peak $\mathrm{H}_{2}$ generation rate of the IDMS run, after which the $\mathrm{H}_{2}$ generation rate will be allowed to decay exponentially (catalyst deactivation) until the total amount of $\mathrm{H}_{2}$ produced is between 85 and $100 \%$ of that produced during the IDMS run.
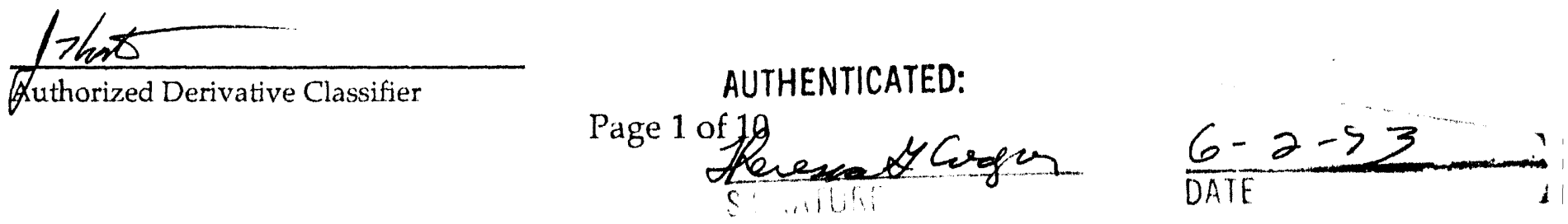


\section{INTRODUCTION}

The Late Wash/Nitric Acid (LW/NA) flowsheet changed not only the amount of $\mathrm{H}_{2}$ being generated in the DWPF CPC but also the peak $\mathrm{H}_{2}$ generation level and induction period compared to the HAN/Formic Acid (FA) flowsheet. ${ }^{1,2}$ In all of the bench and IDMS demonstrations of the LW/NA flowsheet the total amount of $\mathrm{H}_{2}$ produced and the peak $\mathrm{H}_{2}$ generation rate were less and the induction period was greater when compared to comparable HAN/FA flowsheet runs. ${ }^{2,3}$ Nevertheless, the possibility of a deflagration/detonation occurring in the PVV of the DWPF CPC still exists as a result of process modifications.

The modifications planned for the PVV of the DWPF CPC are the result of the $\mathrm{H}_{2}$ design basis for radioactive operations. This design basis requires that a significant amount of purge air be supplied to the CPC vessels in order to control the $\mathrm{H}_{2}$ concentration by fuel dilution. ${ }^{1}$ This purge air, in turn, resulted in an increase in the piping size (from 3 to 6 in diameter) throughout the PVV in order to minimize the pressure drop in the lines. This piping size change coupled with the changes in the flowsheet warranted revisiting the deflagration/detonation issue in the PVV of the DWPF CPC. ${ }^{4}$

The objective of this report is to generate the bases for a simulation of a deflagration/detonation in the DWPF CPC. The simulation will be performed by Professor Van Brunt from the University of South Carolina. LW/NA flowsheet data from the IDMS facility are presented here for this purpose. IDMS run PX5 represents extremely conservative conditions as this run considered all the possible credible deviations from nominal operating conditions that could increase the $\mathrm{H}_{2}$ generation rate. IDMS run PX4, on the other hand, represents a run that was operated at conditions much closer to the nominal operating conditions, but slightly less $\mathrm{H}_{2}$ was generated compared to what may be expected under truly nominal conditions.

\section{BASES FOR DEFLAGRATION/DETONATION SIMULATION}

For both the HAN/FA and LW/NA flowsheets, the generation of $\mathrm{H}_{2}$ in the SRAT follows a corsistent trend of catalyst activation followed by catalyst deactivation. The catalyst has been observed to activate in a somewhat exponential fashion, where the $\mathrm{H}_{2}$ generation rate continuously increases and reaches a peak. Then, catalyst deactivation occurs and the $\mathrm{H}_{2}$ generation rate begins to decrease according to a first order or exponential relationship in time. Based on this experimental evidence, for the LW/NA flowsheet, the scenario which leads up to the deflagration/detonation simulation will be chosen such that the following conditions apply.

The SRAT is filled to its maximum operating level with 9,600 gal of sludge, which corresponds to the minimum vapor space above the sludge. The SRAT is at the boiling point, producing $\mathrm{H}_{2}$ at a very low rate (ubout $10 \%$ of the peak) and $15 \mathrm{scfm}$ of air inleakage is entering the SRAT. Then, the $\mathrm{H}_{2}$ generation rate will be allowed to increase exponentially (catalyst activation) until it reaches the peak $\mathrm{H}_{2}$ generation rate of the 
IDMS run, after which the $\mathrm{H}_{2}$ generation rate will be allowed to decay exponentially (catalyst deactivation) until the total amount of $\mathrm{H}_{2}$ produced is between 85 and $100 \%$ of that produced during the IDMS run.

The data for the $\mathrm{H}_{2}$ generation rate exponentially increasing, peaking and undergoing a first order decay were obtained from two IDMS demonstrations of the LW/NA flowsheet. As mentioned previously, IDMS PX5 represents a very conservative upper limit on the generation of $\mathrm{H}_{2}$ from the LW/NA flowsheet, whereas IDMS PX4 represents a nominal situation. The main differences between these two runs were operational differences that affected the $\mathrm{H}_{2}$ generation rate. ${ }^{1}$

IDMS PX4 was operated at nearly nominal operating conditions except for the way in which the addition/concentration of the PHA was carried out. The batchwise addition/concentration procedure coupled with the low boil-up rate more than likely resulted in a lower peak $\mathrm{H}_{2}$ generation rate compared to that which would have resulted if truly nominal operating conditions were employed. PX5, on the other hand, was operated in such a way as to account for all of the known credible deviations from the nominal operating conditions that could increase the $\mathrm{H}_{2}$ generation rate. This included an over-batching of the PHA added by $30 \%$, using a continuous PHA addition/concentration procedure and using a $72 \%$ higher than normal boil-up rate. For these reasons, a truly nominal peak $\mathrm{H}_{2}$ generation rate along with the corresponding induction period should lie somewhere between that observed from these two IDMS runs.

\section{RESULTS AND DISCUSSION}

The data presented graphically below are given in terms of the IDMS scale, only. This includes the exponential functions displayed in each of the figures. To convert the IDMS $\mathrm{H}_{2}$ generation rate data to the DWPF scale, the following scaling factor must be used: $\mathrm{H}_{2}(\mathrm{lb} / \mathrm{hr}$ DWPF $)=7.4{ }^{*} \mathrm{H}_{2}$ (lb/hr IDMS). This scaling factor was based on 6,000 gal of sludge in the DWPF SRAT compared to $1,100 \mathrm{gal}$ in the IDMS SRAT, and a factor to scale the wt \% solids to that expected as an upper limit at DWPF (i.e., from about 14 to 19 wt \% solids).

The $\mathrm{H}_{2}$ generation rate and temperature profiles obtained during PHA addition/ concentration of IDMS PX5 are shown in Figure 1. Note that the elapsed time corresponds to the start of nitric acid addition. This graph shows that the peak $\mathrm{H}_{2}$ generation rate occurred at about $45 \mathrm{hr}$ and was $0.088 \mathrm{lb} / \mathrm{hr}$ (IDMS scale). Just before that time the $\mathrm{H}_{2}$ generation rate was increasing in a somewhat exponential fashion (Box A). Just after that time and a brief process interruption (indicated by the decrease in temperature and sharp drop in the $\mathrm{H}_{2}$ generation rate), the characteristic first order decay of the $\mathrm{H}_{2}$ generation rate was exhibited (Box $B$ ). The data sets in Boxes $A$ and $B$ were fitted to exponential functions-one function to correlate the increasing $\mathrm{H}_{2}$ generation rate and the other function to correlate the decreasing $\mathrm{H}_{2}$ generation rate. The results are shown in Figures 2 and 3, respectively. 


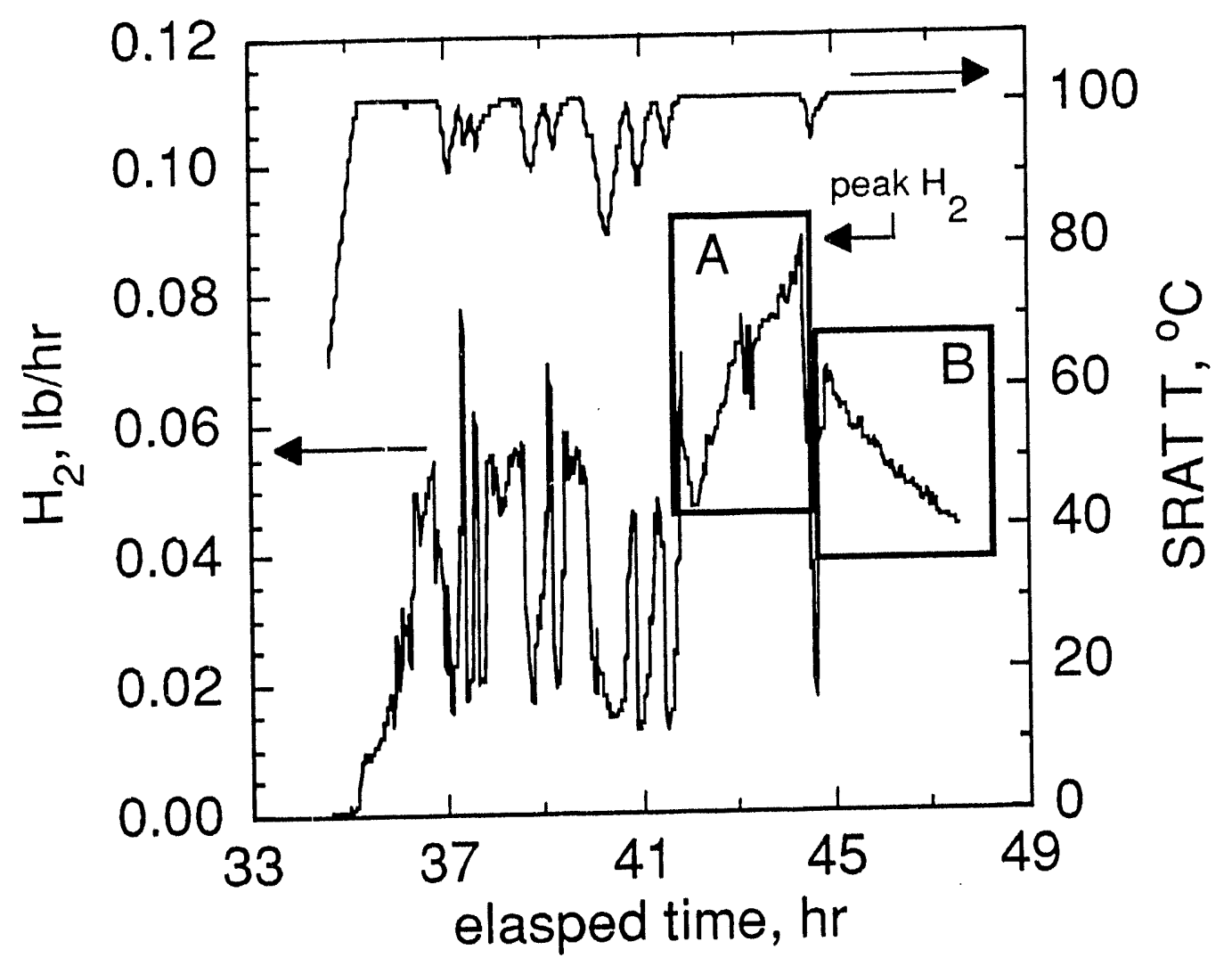

Figure 1. IDMS PX5: hydrogen generation rate and SRAT temperature. Box A corresponds to data shown in Figure 2 and Box B corresponds to data shown in Figure 3.

Figure 2 displays a representative sampling of the data from Box A in Figure 1. These data were fitted to an exponential function which resulted in a first order time constant of $3.77 \times 10^{-3} \mathrm{~min}^{-1}$. This function should be used until the $\mathrm{H}_{2}$ generation rate peaks at $8.83 \times 10^{-2} \mathrm{lb} / \mathrm{hr}$ (see Figure 1). In order to start the simulation, the $\mathrm{H}_{2}$ generation rate at $\mathrm{t}=0$ must be selected. It is suggested that the $\mathrm{H}_{2}$ generation rate at $\mathrm{t}=0$ corresp ond to about $10 \%$ of the observed peak $\mathrm{H}_{2}$ generation rate.

Figure 3 displays a representative sampling of the data from Box B in Figure 1. These data were fitted to an exponential function which resulted in a first order time constant of $-2.45 \times 10^{-3} \mathrm{~min}^{-1}$. With the aforementioned assumption that a first order decay of the $\mathrm{H}_{2}$ generation rate always occurs after the $\mathrm{H}_{2}$ generation rate peaks, this time constant and the peak $\mathrm{H}_{2}$ generation rate $\left(8.83 \times 10^{-2} \mathrm{lb} / \mathrm{hr}\right.$, see Figure 1$)$ were combined to obtain the exponential inction indicated and plotted as the heavy solid line in Figure 3.

The exponential functions shown in Figures 2 and 3 represent the increase, peak and decrease in the $\mathrm{H}_{2}$ generation rate for the extreme case in the simulation of a 
deflagration/detonation in the PVV of the DWPF CPC. For this case, the total production of $\mathrm{H}_{2}$ integrated over the entire SRAT cycle was $7.4 \mathrm{lb}$ (DWPF scale) and the peak $\mathrm{H}_{2}$ generation rate was $0.64 \mathrm{lb} / \mathrm{hr}$ (DWPF scale). The nearly nominal case corresponds to the data from PX4, where $5.2 \mathrm{lb}$ of $\mathrm{H}_{2}$ (DWPF scale) were produced during the entire cycle and the peak was only $0.2 \mathrm{lb} / \mathrm{hr}$ (DWPF scale). This data is shown in Figure 4.

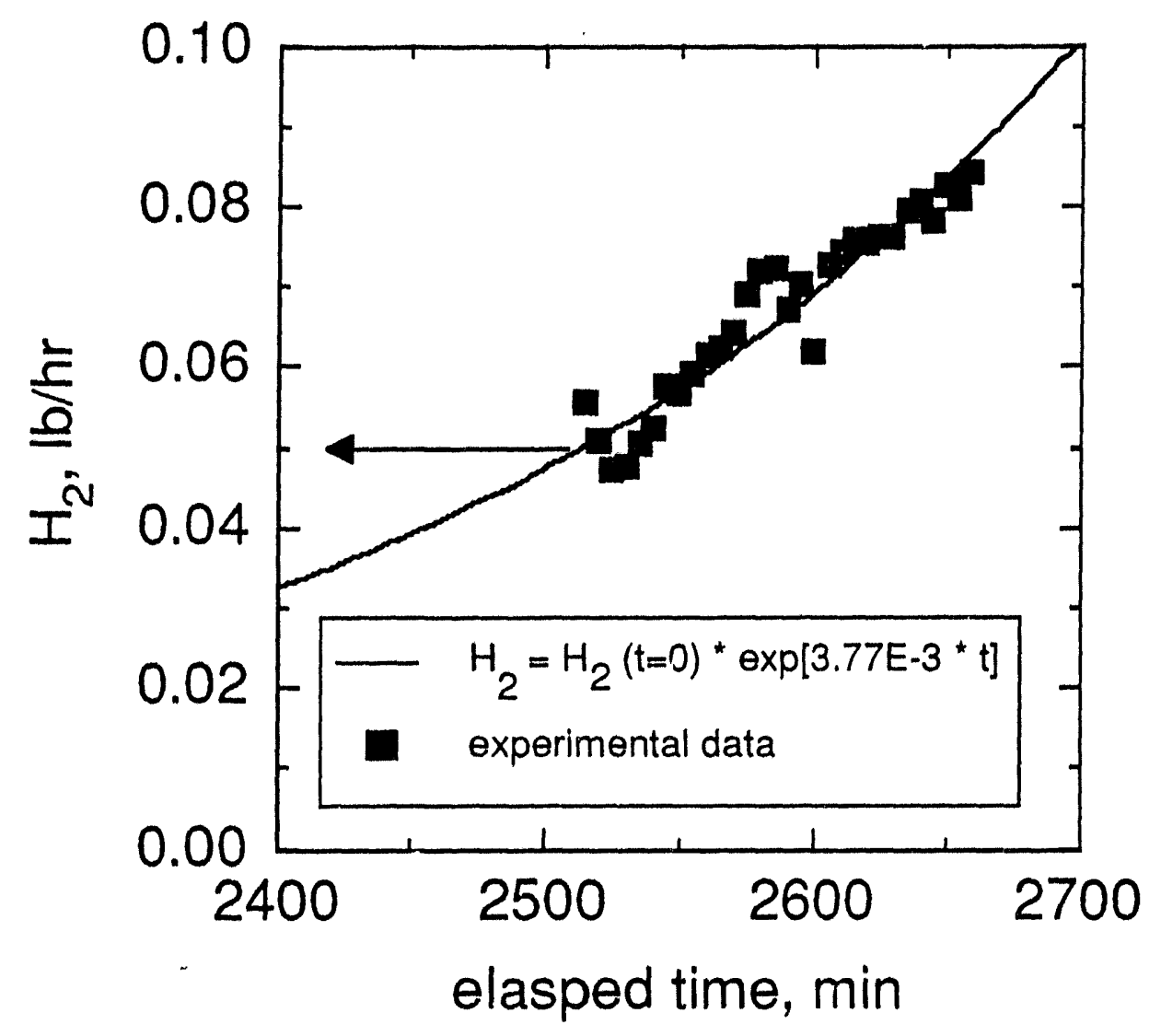

Figure 2. IDMS PX5: increase in the hydrogen generation rate at boiling conditions just before peak occurred (data correspond to Box A in Figure 1). For an assummed $t=0$, the preexponential coefficient of the function for the hydrogen generation rate should be selected from the curve, e.g., the arrow in the figure indicates $\mathrm{H}_{2}($ at $\mathrm{t}=0)=0.05$.

Figure 4 shows the $\mathrm{H}_{2}$ generation rate and temperature profiles obtained during PHA addition/concentration of IDMS PX4. Note that the elapsed time corresponds to the start of nitric acid addition. This graph shows that the peak $\mathrm{H}_{2}$ generation rate occurred 
at about $80 \mathrm{hr}$ compared to $45 \mathrm{hr}$ for PX5. Moreover, the peak $\mathrm{H}_{2}$ generation rate was much less. The suspected causes of the differences between these two runs were given earlier. As with PX5, the data sets in Boxes A and B were fitted to exponential functions. The results are shown in Figures 5 and 6, respectively.

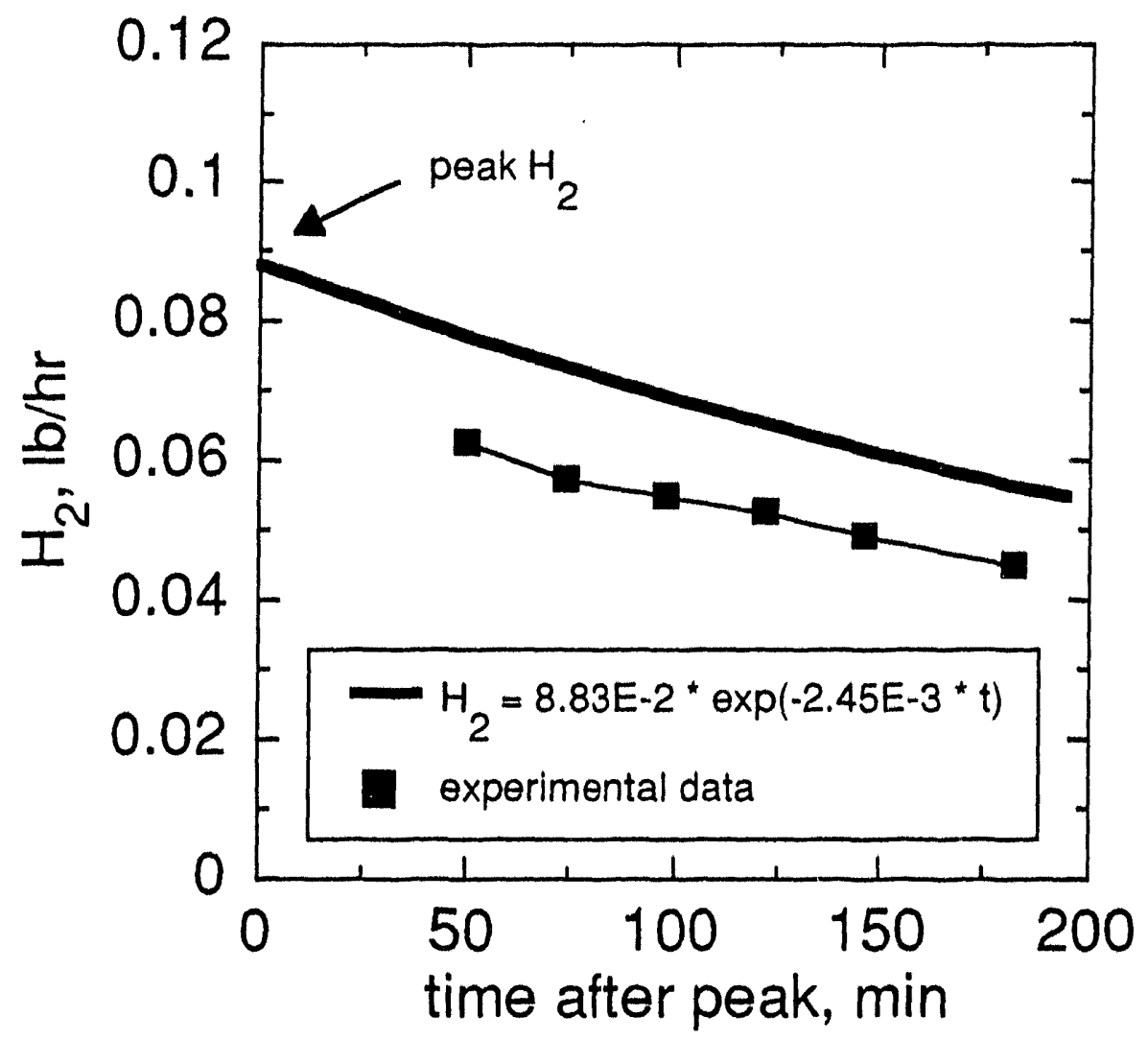

Figure 3. IDMS PX5: Lower curve and symbols represent the decay of the hydrogen generation rate at boiling just after peak occurred data correspond toBox B in Figure 1). Upper curve corresponds to same decay rate as data but adjusted for the peak hydrogen generation rate at $\mathrm{t}=0$ (see Figure 1 , peak $\mathrm{H}_{2}$ arrow).

Figure 5 displays a representative sampling of the data from Box $A$ in Figure 4. These data were fitted to an exponential function which resulted in a first order time constant of $4.94 \times 10^{-3} \mathrm{~min}^{-1}$. This function should be used until the $\mathrm{H}_{2}$ generation rate peaks at $2.20 \times 10^{-2} \mathrm{lb} / \mathrm{hr}$ (see Figure 4). Once again, in order to start the simulation, the $\mathrm{H}_{2}$ generation rate at $\mathrm{t}=0$ must be selected. It is again suggested that the $\mathrm{H}_{2}$ generation rate at $\mathrm{t}=0$ correspond to about $10 \%$ of the observed peak $\mathrm{H}_{2}$ generation rate. 
Figure 6 displays a representative sampling of the data from Box B in Figure 4. These data were fitted to an exponential function which resulted in a first order time constant of $-1.71 \times 10^{-3} \mathrm{~min}^{-1}$. Because there was no interruption in the process just after the peak $\mathrm{H}_{2}$ generation rate occurred, there was no need to adjust the data and the peak $\mathrm{H}_{2}$ generation rate $\left(2.20 \times 10^{-2} \mathrm{lb} / \mathrm{hr}\right)$ was used directly in the correlation.

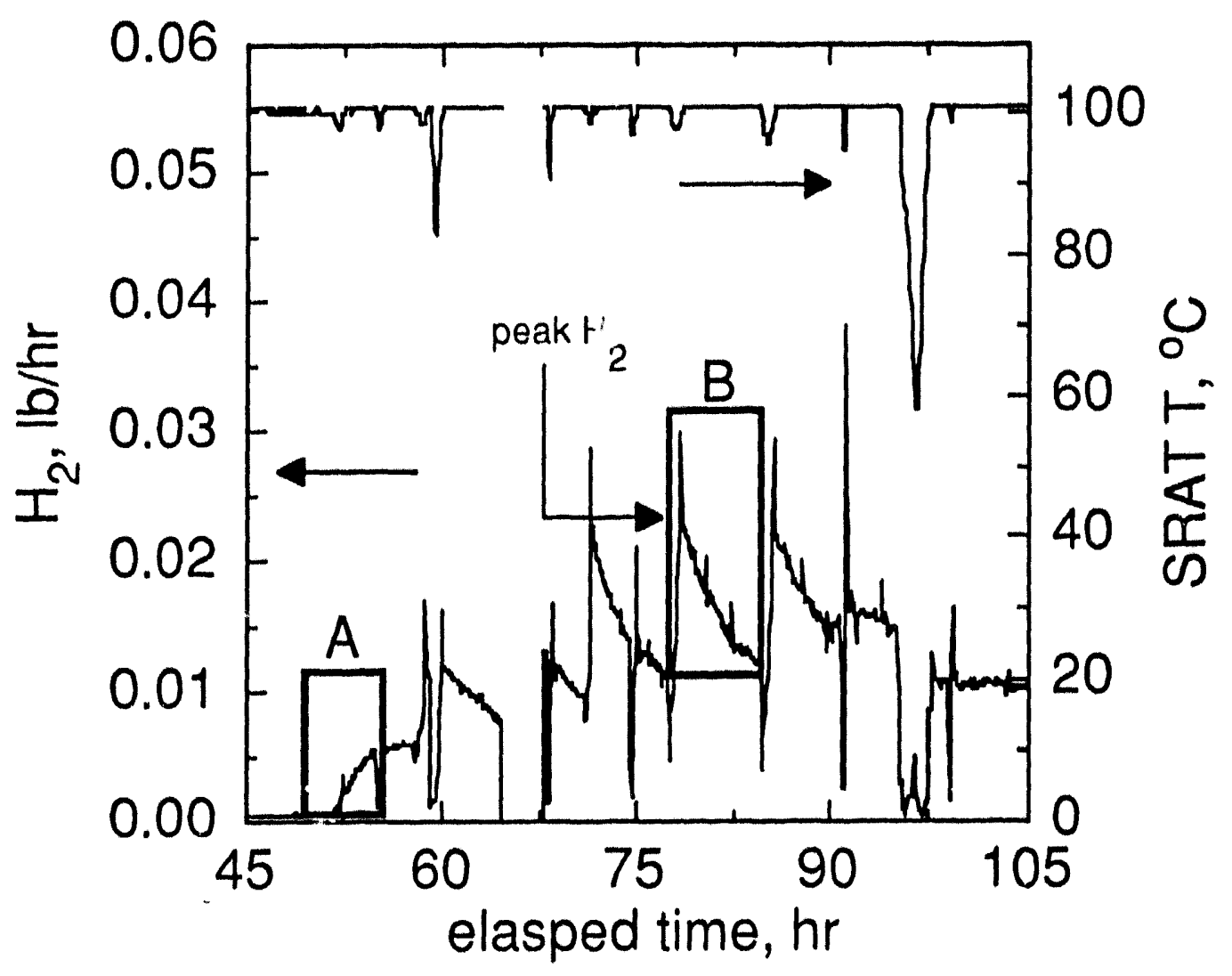

Figure 4. IDMS PX4: hydrogen generation rate and SRAT temperature. Box A corresponds to data shown in Figure 5 and Box B corresponds to data shown in Figure 6.

It should be noted that the time constant for the increasing $\mathrm{H}_{2}$ generation rate during PX4 was about $30 \%$ larger than that for PX5. This result was an artifact of the arbitrary selection of the data chosen for the correlation of PX4 (see Figure 4). It is clear from the data shown in Figures 1 and 4 that PX5 exhibited well behaved data that increased and decreased around the peak $\mathrm{H}_{2}$ generation rate. This was not the case for PX4. So, for PX4, the data was chosen at the onset of the $\mathrm{H}_{2}$ generation rate. The effect of this choice 
on the simulation should be minimal, however, and only makes the simulation using PX4 data more conservative.

The correlations generated from the IDMS PX5 data were used to create the profiles shown in Figure 7 for the $\mathrm{H}_{2}$ generation rate and cumulative amount of $\mathrm{H}_{2}$ generated in the SRAT during PHA transfer. For this scenario, the $\mathrm{H}_{2}$ generation rate at $\mathrm{t}=0$ was arbitrarily chosen as $0.074 \mathrm{lb} / \mathrm{hr}$ (DWPF scale), which was only slightly larger than $10 \%$ of the peak $\mathrm{H}_{2}$ generation rate. The peak $\mathrm{H}_{2}$ generation rate and the total amount of $\mathrm{H}_{2}$ generated both corresponded to that actually generated during IDMS PX5, scaled to DWPF. Also, the $30 \mathrm{hr}$ time span corresponded to a typical PHA transfer time, if 12,000 gal of PHA are added at about $7 \mathrm{gal} / \mathrm{min}$. It should be $\mathrm{mphasized} \mathrm{that} \mathrm{this} \mathrm{simple} \mathrm{but}$ realistic scenario only serves as an example that may be (but need not be) followed by Van Brunt in his study. ${ }^{4}$

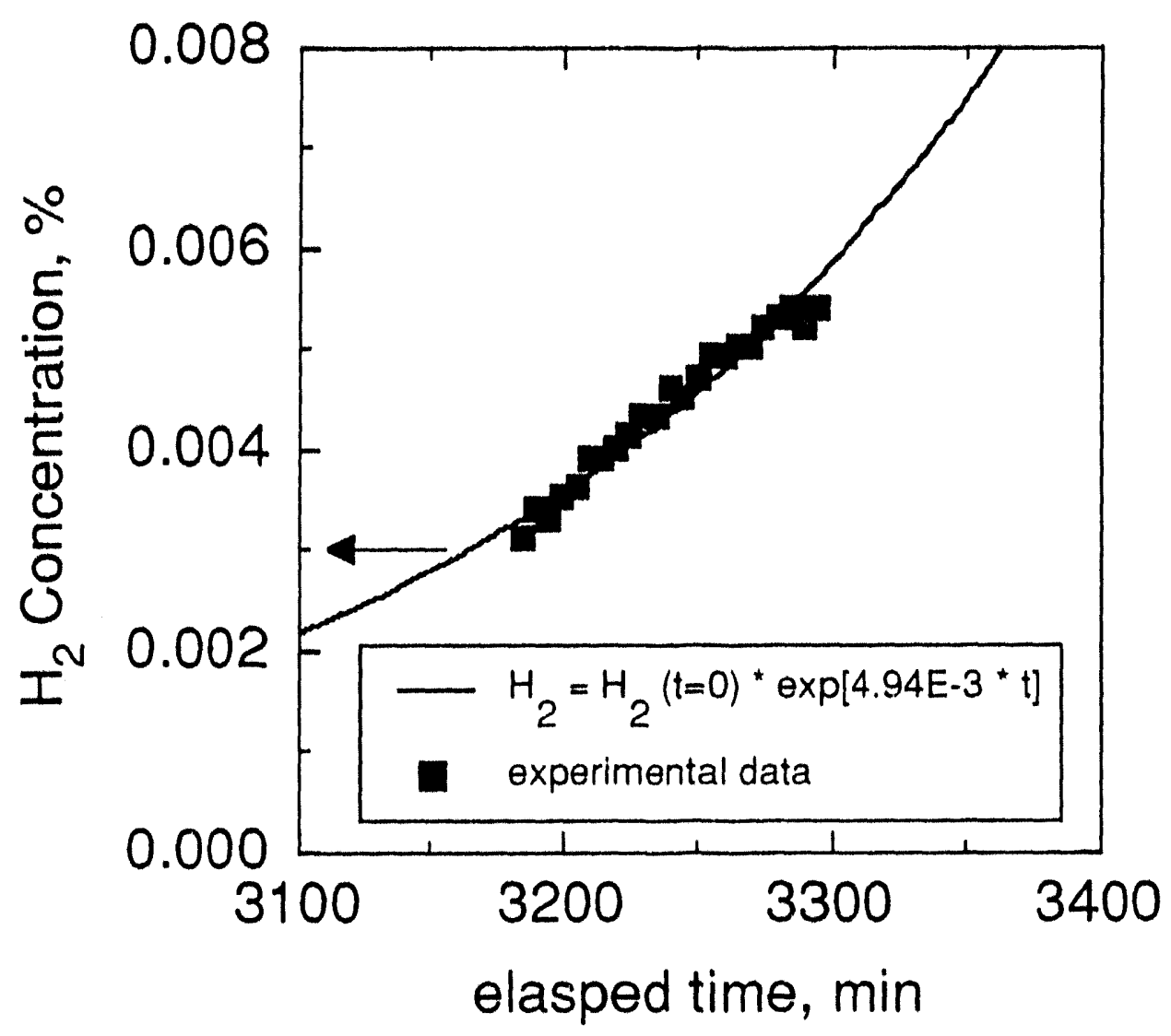

Figure 5. IDMS PX4: initial increase in the hydrogen generation rate at boiling conditions before peak occurred (data correspond to box $A$ in Figure 4). For an assummed $t=0$, the preexponential coefficient of the function for the hydrogen generation rate should be selected from the curve, e.g., the arrow in the figure indicates $\mathrm{H}_{2}($ at $\mathrm{t}=0)=0.003$. 


\section{CONCLUSION}

Data obtained from IDMS runs PX4 and PX5 for the generation of $\mathrm{H}_{2}$ were used to determine a bases for a deflagration/detonation simulation in the DWPF C.PC. The sir ulation will be performed by Professor Van Brunt from the University of South Carolina. This simulation is necessary due to the new chemistry associated with the Late Wash/Nitric Acid flowsheet and process modifications associated with the presence of $\mathrm{H}_{2}$ in the offgas. IDMS PX5 represented extremely conservative conditions, whereas IDMS PX4 represented conditions much closer to the nominal. For both IDMS runs, exponential functions were correlated with the increasing and decreasing $\mathrm{H}_{2}$ generation rate data. Prior to performing the deflagration/detonation simulation, these functions will be used to determine the peak $\mathrm{H}_{2}$ concentration and the total amount of $\mathrm{H}_{2}$ in the system, based on a scenario similar to that described in the text.

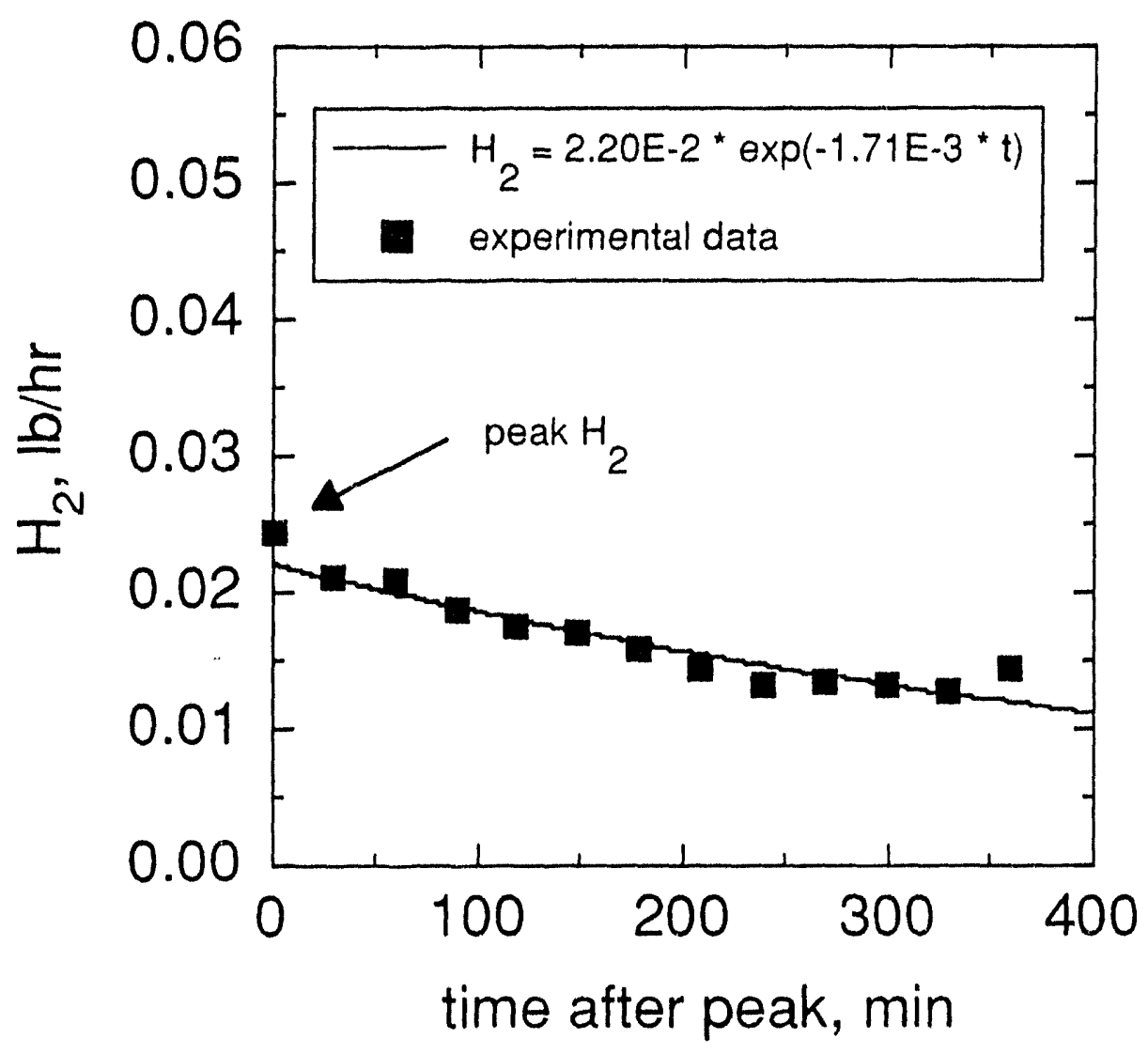

Figure 6. IDMS PX4: decay of the hydrogen generation rate at boiling just after highest peak occurred (data correspond to Box B in Figure 4). At $t=0$, the preexponential coefficient corresponds to the peak value (see Figure 4). 


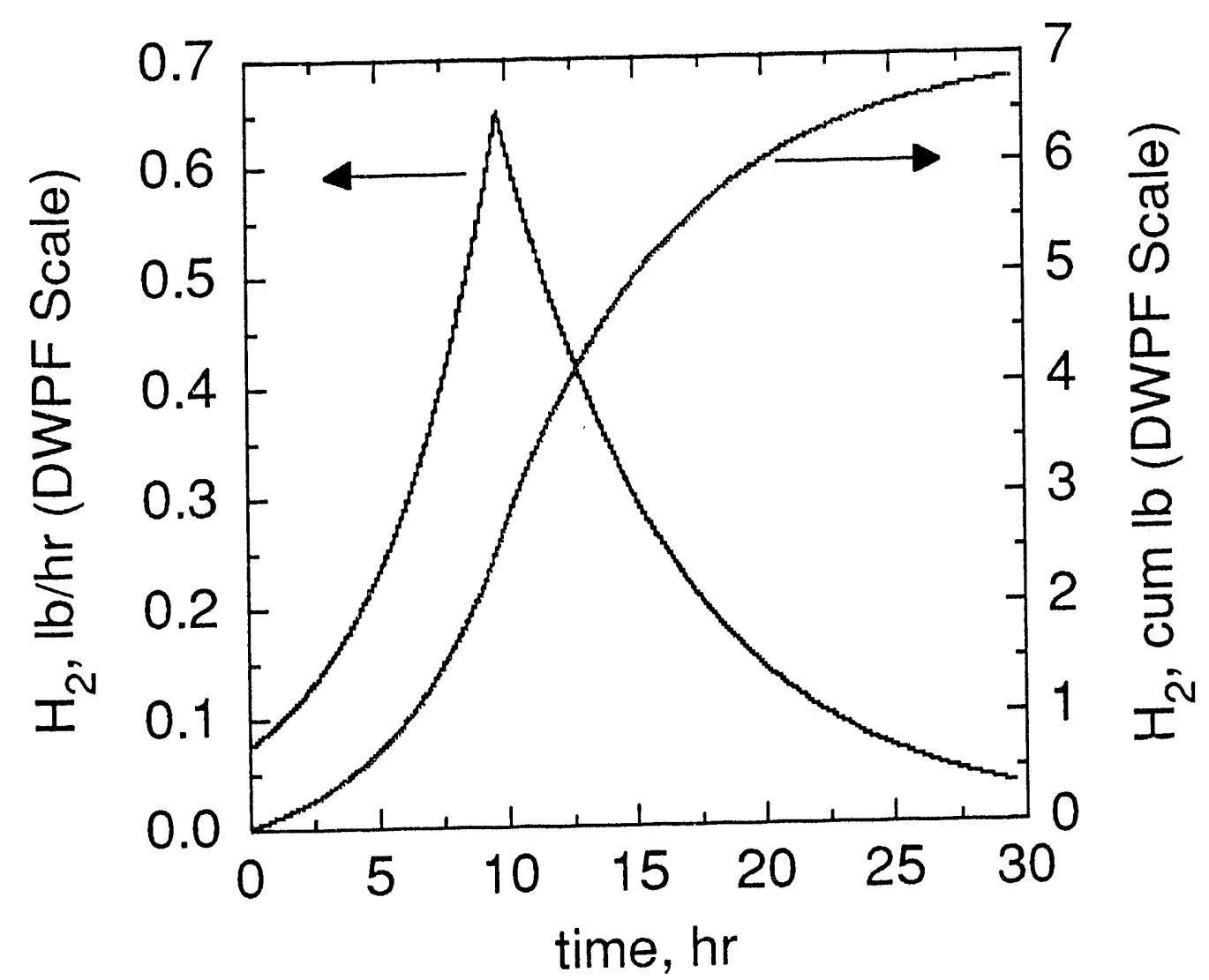

Figure 7. A typical scenario representing the $\mathrm{H}_{2}$ generation rate and cummulative amount of $\mathrm{H}_{2}$ generated in the SRAT during PHA transfer, based on the IDMS PX5 functions scaled to DWPF conditions (the $\mathrm{H}_{2}$ generation rate at $\mathrm{t}=0$ was abitrarily chosen as $0.074 \mathrm{lb} / \mathrm{hr}$ DWPF scale).

\section{REFERENCES}

1. J. A. Ritter, "Hydrogen Generation during IDMS Demonstrations of the Late Washing and Nitric Acid Flowsheets", WSRC-RP-92-1237.

2. J. A. Ritter, J. R. Zamecnik and C. W. Hsu, "Hydrogen Generation during Treatment of Simulated High-Level Radioactive Waste with Formic Acid", WSRC-MS-92-0017.

3. C. W. Hsu and J. A. Ritter, "Study on Hydrogen Evolution during Treatment of SRS High-Level Radioactive Sludge Simulant with Formic Acid", WSRC-MS-92-0270.

4. V. Van Brunt, "Hazard Analysis of Hydrogen Evolution in DWPF Process Vessels and Vent System", USC-SCUREF-15-1-92. 

